\title{
Libertad de conciencia y discusiones valóricas en el contexto de Estados seculares. Aportes desde la teología católica
}

Este comentario, junto a los documentos que analiza, está disponible en www.anuariocdh.uchile.cl

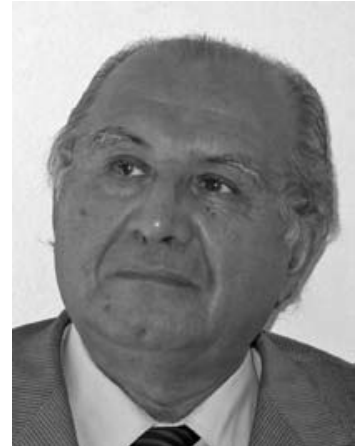

\begin{abstract}
Waldo Romo
Magíster en Teología por la Universidad Católica y especialización en Moral por el Instituto Superior de Ciencias Morales de Madrid. Actualmente, profesor de Moral de la Persona (moral sexual y moral de la vida) en la Facultad de Teología y profesor de Teología del Matrimonio en la misma Facultad y en el Seminario Pontificio Mayor. Coautor del libro "El misterio de la sexualidad humana" y autor de diversos artículos en temas de su especialidad. Fue Vicedecano de la Facultad de Teología y asesor de la Comisión Doctrinal del Episcopado chileno. Durante el gobierno del Presidente Aylwin integró la Comisión Nacional de la Familia y durante el gobierno del Presidente Lagos fue miembro de la Comisión de evaluación y recomendaciones sobre educación sexual, entidad creada por el Ministro de Educación de la época.
\end{abstract}

wromo@uc.cl

\section{RESUMEN}

El ejercicio de la libertad de conciencia y, particularmente, la injerencia de la Iglesia Católica en los debates valóricos del mundo secular, está fuertemente marcada por su relación con el Estado. Desde la escisión entre ambas instituciones, fenómeno que tiene sus inicios -en Occidente- en el Renacimiento y la Reforma, la Iglesia ha debido revisar y ajustar su posición. La renovación teológica ocurrida a partir del Concilio Vaticano II dentro de ella ha sido fundamental en esta revisión y ajuste. El artículo revisa cuál ha sido este proceso y fundamenta la legitimidad de la intervención de la Iglesia Católica en los debates valóricos.

\section{Mirada histórica}

La adecuada comprensión del tema requiere analizarlo, brevemente, desde una perspectiva histórica. En efecto, la existencia en Occidente de Estados seculares es una realidad que se inaugura, en la práctica, a partir del siglo XVI con el Renacimiento y la Reforma. El primero desplaza el teocentrismo medieval occidental hacia el foco antropocéntrico y la segunda rompe la unidad religiosa europea en torno a la Iglesia Católica, concluyendo con un modelo que comenzó con Constantino (s. IV) y que permitió la elaboración agustiniana de la relación Iglesia-Estado consagrada en la Civitas Dei y continuada, con algunos matices, en el tomismo del siglo XIII.

Estos dos fenómenos -Reforma y Renacimiento- están relacionados. Al romperse la cristiandad medieval se fractura una visión piramidal de la sociedad con Dios en la cúspide, quien manifiesta su pensamiento por medio de la Iglesia Católica, a la cual están sometidos los Estados. Es esta Iglesia la que presenta una cosmovisión del mundo y define los valores morales a los que deben adherir los miembros de la ciudad de los hombres cuyo destino definitivo es, sin embargo, la Ciudad de Dios. Por su parte, el desplazamiento de un teocentrismo a un antropocentrismo hace emerger, progresivamente, el valor de la conciencia personal y las decisiones que puedan tomarse desde 
ese centro intransferible. El "yo pienso, luego existo" cartesiano inaugura la filosofía moderna y con él la seriedad con que el ser humano se toma a sí mismo y lo que él elabora.

Le fue difícil a la Iglesia Católica asumir este desplazamiento. Donde pudo mantener su hegemonía, procuró sostenerla. Fue el caso del mundo lusitano-español con sus colonias. Luego convino de "poder a poder" en la relación Iglesia-Estado. Procuró, así, establecer -donde fue posibleConcordatos para materias que le eran especialmente sensibles (educación, matrimonio). También se amparó en la enseñanza de una "ley natural" (doctrina de antigua data) que permitía un punto de encuentro entre creyentes y no creyentes, aunque la definición de su contenido parecía reservarse, para sí, la propia Iglesia Católica en cuanto la entendía vinculada a la ley divina.

Para proponer una reflexión equilibrada, es necesario detenerse someramente en la actitud de ese mundo que se va autonomizando legítimamente. En algunos, muchas actitudes son consecuencia de una reacción enconada y beligerante ante una Iglesia Católica vista como detentora de un poder abusivo o coludida con los "grandes" de este mundo. Surge una Revolución Francesa erigida bajo la presidencia de la Diosa Razón, se elaboran los derechos humanos individuales planteados en cenáculos racionalistas críticos a su fundamentación religiosa y a la misma Iglesia. Esta criticidad beligerante se traduce hoy, y en el contexto de la globalización, en la aspiración, para algunas corrientes, por construir un nuevo orden mundial presidido por un humanismo secular, prescindente del aporte religioso.

\section{Los planteamientos del Concilio Vaticano II}

Este evento eclesial del siglo pasado es fundamental para entender la comprensión que la propia Iglesia Católica tiene de sí misma en su relación con el mundo moderno. Se pretende un aggiornamento de la Iglesia que, aplicado a nuestro tema, implica una nueva manera de entender la relación Iglesia-Estado, que procura que la armonía entre ser cristiano y ser contemporáneo sólo sufra la tensión inscrita en el Evangelio: "estar en el mundo y no ser del mundo". Dicha actualización estuvo preparada -antes del Concilio- por una ingente renovación en diversos campos al interior eclesial. Ello testimoniaba la insatisfacción de los grupos más comprometidos con el modo de entender la inserción del cristiano en el mundo y con la necesidad de superar una visión de cristiandad ya inexistente.

Este "nuevo Pentecostés" -como sugerentemente Ilamó Juan XXIII al Concilio Vaticano II- se ha expresado en diversos documentos. Interesa detenerse en dos que son claves para entender la renovación en la materia estudiada: la Constitución Pastoral "La Iglesia en el mundo de hoy" (Constitución Gaudium et Spes. GS) y la Declaración sobre Libertad religiosa (Declaración Dignitatis humanae. DH).

La GS es una de las principales Constituciones (documentos mayores) elaboradas por el Concilio y su objetivo preciso es proponer una visión renovada de la fe católica y de la Iglesia en su diálogo con el mundo. Incluso, siguiendo la historia del texto, se sabe que al interior del debate conciliar los primeros esquemas de este documento -elaborados desde un enfoque tradicional- no recogieron la aprobación de los padres conciliares. Fue necesario reformular el esquema desde sus bases haciendo posible la aprobación, en definitiva, de un enfoque que ha implicado una verdadera "revolución copernicana" a la antigua mirada de la cristiandad. En este esfuerzo de diálogo conviene conocer los principales planteamientos renovados de uno de los dialogantes que es la Iglesia Católica, siguiendo el aporte de GS. Como es obvio, ellos arrancan de una concepción creyente en que la persona es considerada la creatura más amada de Dios:

a) La dignidad de la conciencia moral. GS la describe como "el núcleo más secreto y el sagrario del ser humano, en el que está solo con Dios, cuya voz resuena en lo más íntimo de ella. Por 
la conciencia, se conoce de un modo admirable aquella ley cuyo cumplimiento consiste en el amor a Dios y al prójimo. La fidelidad a esta conciencia une a los cristianos con los demás hombres para buscar la verdad y resolver en la verdad tantos problemas morales [individuales y sociales]"1.

b) La grandeza de la libertad.

"El ser humano sólo libremente puede convertirse al bien, con esa libertad que nuestros contemporáneos tanto estiman y buscan con entusiasmo: y ciertamente con razón. Sin embargo, muchas veces la fomentan de un modo depravado como si fuese una licencia para hacer todo lo que les agrada aunque sea malo. La verdadera libertad es signo eminente de la imagen divina en la persona humana. Pues quiso Dios 'dejar al hombre en manos de su propia decisión' ${ }^{2}$, de modo que busque sin coacciones a su Creador y, adhiriéndose a Él, Ilegue libremente a la plena y feliz perfección. La dignidad del ser humano requiere, en efecto, que actúe según una elección consciente y libre, es decir, movido e inducido personalmente desde dentro y no bajo la presión de un ciego impulso interior o de la mera coacción externa" ${ }^{3}$.

c) La distinción importante entre una justa y una distorsionada autonomía de "lo temporal":

"Si por autonomía de las realidades terrenas entendemos que las cosas creadas y las sociedades mismas gozan de leyes y valores propios que el ser humano ha de descubrir, aplicar y ordenar paulatinamente, exigir esa autonomía es completamente lícito. No sólo lo reclaman así los hombres de nuestro tiempo, sino que está también de acuerdo con la voluntad de Dios [...] Pero si con las palabras 'autonomía de las realidades temporales' se entiende que las cosas creadas no dependen de Dios y que el hombre puede utilizarlas sin referirlas al Creador, todo el que conoce a Dios siente hasta qué punto son falsas las opiniones de este tipo" ${ }^{4}$.

d) El reconocimiento del aporte que el mundo hace a la Iglesia y que ésta otorga a aquél (cf. GS 43 y 44). Es decir, la Constitución trata la relación en términos de mutua colaboración.

e) Del número 73 a 76 GS se refiere explícitamente a la vida de la comunidad política, donde se destaca lo que el documento dice sobre la naturaleza y fin de la comunidad política, la necesidad de que todos cooperen en la vida pública y la relación entre la comunidad política y la Iglesia. Dada la naturaleza de este trabajo, conviene destacar en este número (GS, 76) algunos aspectos: "Es de gran importancia, sobre todo allí donde exista una sociedad pluralista, que se tenga un recto concepto de la relación entre comunidad política e Iglesia y que se distinga claramente entre aquello que los fieles cristianos hacen, individual o colectivamente, en su nombre en cuanto ciudadanos, guiados por la conciencia cristiana, y lo que hacen en nombre de la Iglesia juntamente con sus pastores". Más adelante señala: "La Iglesia, que en razón de su función y de su competencia no se confunde de ningún modo con la comunidad política y no está ligada a ningún sistema político, es al mismo tiempo signo y salvaguardia de la trascendencia ${ }^{5}$ de la persona humana. La comunidad política y la Iglesia son entre sí independientes y autónomas en su propio campo". Ambas, aunque a título diverso, están al servicio de las personas, el que se realizará de mejor forma cuando haya cooperación entre Iglesia y Estado.

\footnotetext{
GS, 16.

Cf. Libro del Eclesiástico 15,14.

GS, 17.

GS, 36.

5 El destacado pertenece al autor del artículo.
} 
f) Por la importancia que tiene en las aplicaciones concretas de este trabajo se destaca, de modo aparte, un aporte del mismo número comentado: "[la Iglesia] no pone su esperanza en privilegios otorgados por la autoridad civil; más aún, renunciará al ejercicio de algunos derechos legítimamente adquiridos cuando conste que con su uso se pone en tela de juicio la sinceridad de su testimonio o que las nuevas condiciones de vida exigen otra ordenación. Pero la Iglesia debe poder, siempre y en todo lugar, predicar la fe con verdadera libertad... y emitir un juicio moral también sobre cosas que afectan al orden político cuando lo exijan los derechos fundamentales de la persona o la salvación de las almas, aplicando todos y sólo aquellos medios que sean conformes al Evangelio y al bien de todos según la diversidad de tiempos y condiciones" ${ }^{6}$.

La Iglesia pide, entonces, que se respete su derecho a decir su palabra en diversos ámbitos, incluido el campo moral con incidencia en lo político. En una sociedad pluralmente religiosa ese derecho, como es lógico, no se reclama exclusivamente para ella. Quiere ser un actor más en el debate plural de las ideas. Manifiesta, además, que al expresar su palabra opta por usar sólo los medios conformes al Evangelio, es decir, eligiendo el camino del ofrecimiento de sentido, de la persuasión, de la argumentación racional y razonable y renuncia a "derechos legítimamente adquiridos" si eso entorpece la transparencia de su mensaje. En este ofrecimiento de sentido, una dimensión decisiva que la Iglesia quiere aportar -no imponer- es proponer una visión integral de la persona humana, la cual no se reduce a una dimensión inmanente de su destino sino que la abre a una dimensión trascendente, hacia un Absoluto que da la clave de comprensión de la persona y de la sociedad.

Esta apertura se ha expresado de diversas maneras en el pensamiento teológico católico postconciliar: desde el categórico transcendental de Karl Rahner hasta la afirmación de Henry de Lubac, citado por Pablo VI en la mencionada Encíclica y formando parte de su número 42: "Es un humanismo pleno el que hay que promover. ¿Qué quiere decir esto sino el desarrollo integral de todo el hombre y de todos los hombres? Un humanismo cerrado, impenetrable a los valores del espíritu y a Dios que es la fuente de ellos, podría aparentemente triunfar. Ciertamente el hombre puede organizar la tierra sin Dios, pero 'al fin y al cabo, sin Dios no puede menos de organizarla contra el hombre. El humanismo exclusivo es un humanismo inhumano' ${ }^{8}$. No hay, pues, más que un humanismo verdadero que se abre al Absoluto, en el reconocimiento de una vocación, que da la idea verdadera de la vida humana. Lejos de ser la norma última de los valores, el hombre no se realiza a sí mismo si no es superándose. Según la tan acertada expresión de Pascal: 'el hombre supera infinitamente al hombre ${ }^{\prime \prime \prime 9}$. Esta aspiración de Absoluto, de trascendencia del ser humano más allá de sí mismo, se ha dado en todas las culturas, desde la religiosidad primitiva de la Pachamama hasta el monoteísmo, incorporando, también, el deseo de Dios en el ateísmo marxista o en el gran arquitecto masónico.

El segundo documento conciliar que es necesario comentar es la Declaración Dignitatis Humanae, texto crucial para certificar la autenticidad de renovación a la cual aspiraba la Iglesia Católica.

$6 \quad I d$.

7 PABLO VI en la Encíclica Populorum Progressio ya planteaba en 1967 ese ofrecimiento en los siguientes términos: “[La Iglesia] tomando parte en las mejores aspiraciones de los hombres y sufriendo al no verlas satisfechas, desea ayudarles a conseguir su pleno desarrollo y esto precisamente porque ella les propone lo que posee, como propio: una visión global del hombre y de la humanidad", n. 13.

8 Cita de HENRY DE LUBAC, s.j., Le drame de l'humanisme athée, $3^{\mathrm{a}}$ ed., París, Spes, 1945, p. 10. Con una mirada desprejuiciada ante la construcción de "imperios políticos" del siglo XX, se puede constatar -como lo atestigua la historia reciente- que esa construcción sin Dios se ha tornado, en definitiva, contra la persona.

9 Cita del filósofo PASCAL en Pensées, ed. Brunschvicg, nº 434. 
Se debatió mucho su contenido encontrándose dos posiciones, en parte antagónicas, que se mantuvieron a lo largo de las sesiones conciliares.

La reflexión en torno a la libertad religiosa (LR) implicaba enfrentar tres problemas. El jurídico: cuál es la naturaleza y fundamento de la LR; el político: cuál es el límite del ejercicio de la LR y cuál es el criterio de intervención de la autoridad estatal y el teológico: si la LR tiene fundamento en la Sagrada Escritura y cómo se concilia el Magisterio precedente con la declaración de la LR. Ante estos tres problemas,
"[...] se adoptan dos posturas por los Padres conciliares que, en primer lugar, parten de dos experien- cias jurídicas distintas, la anglosajona (especialmente la norteamericana) y la centroeuropea con la latina; y que, en segundo lugar, surgen de dos movimientos eclesiales, centrípeto el uno -que se fija en la Iglesia en sí misma y tiende primordialmente a salvaguardar el depósito de la fe-, y centrífugo el otro -que contempla a la Iglesia ante el mundo dirigida a los demás [...] Las dos posturas parten de un mismo principio fundamental, el dualismo de sociedades-autoridades; es decir, la Iglesia y el Estado son dos comunidades distintas e independientes, cada uno en su orden ${ }^{10}$. Pero divergen en las respuestas a los tres problemas concretos planteados. Así, al problema jurídico: mientras para la $1^{\mathrm{a}}$ sólo hay un derecho natural y sobrenatural para el bien y la verdad revelados, para la $2^{\mathrm{a}}$ el derecho de la LR es un derecho natural, igual para todos. Al problema político: mientras para la $1^{\text {a }}$ el límite es el bien común, comprensivo del bien religioso verdadero, admitiéndose sólo un régimen de tolerancia y, a lo sumo, una libertad civil para todas las religiones, la $2^{\mathrm{a}}$ sostiene que el límite es el orden público, comprendiendo los derechos fundamentales todos, y que el régimen de libertad religiosa es consecuencia del expresado derecho natural. Al problema teológico: mientras para la $1^{\text {a }}$ la LR no tiene fundamento en la Revelación y el Magisterio se ha mantenido inalterable, para la $2^{a}$ ha habido un progreso en el Magisterio respecto a los derechos fundamentales, comprendido el de $L R$, y éste tiene, al menos, raíces en la Revelación"11.

La postura primera recogía, en lo sustantivo, una visión más tradicional y más estrecha en cuanto a la LR; la segunda posición se abría de un modo más renovado a la reflexión en la materia estudiada. El Concilio se inclinó mayoritariamente hacia la segunda postura, tomando sólo algunos elementos insistidos desde la primera. Ello se refleja en dos textos escogidos para este estudio:

"Los hombres de nuestro tiempo tienen una conciencia cada vez mayor de la dignidad de la persona humana y crece el número de los que exigen que los hombres actúen según su propio criterio y hagan uso de una libertad responsable, no movidos por coacción, sino guiados por la conciencia del deber. Piden igualmente la delimitación jurídica del poder público, para que no se restrinjan demasiado los límites de la justa libertad de la persona y de las asociaciones. Esta exigencia de la libertad en la sociedad humana se refiere sobre todo a los bienes del espíritu humano, principalmente a los que afectan al libre ejercicio de la religión en la sociedad"12.

El otro texto señala:

"Este Concilio declara que la persona humana tiene derecho a la libertad religiosa. Esta libertad consiste en que todos los hombres deben estar libres de coacción, tanto por parte de personas particulares como de los grupos sociales y de cualquier poder humano, de modo que en materia religiosa, ni se obligue a nadie a actuar contra su conciencia, ni se le impida que actúe conforme a

10 Principio ya consagrado en la Constitución GS como se ha visto anteriormente.

11 CORRAL SALVADOR, CARLOS, Introducción al documento sobre la Declaración Dignitatis humanae. (Las dos posturas antitéticas ante los tres problemas planteados) en Concilio Ecuménico Vaticano II, Ed. BAC, Madrid, 2004 , p. 981.

12 CONCILIO VATICANO II, Declaración sobre libertad religiosa, 1. 
ella ${ }^{13}$, pública o privadamente, solo o asociado con otros, dentro de los debidos límites. Declara, además, que el derecho a la libertad religiosa está realmente fundado en la dignidad misma de la persona humana, tal como se conoce por la palabra de Dios revelada y por la misma razón. Este derecho de la persona humana a la libertad religiosa debe ser reconocido en el ordenamiento jurídico de la sociedad, de forma que se convierta en derecho civil"14.

Cabe situar, entonces, la libertad religiosa como un auténtico derecho humano desde el momento en que no se funda en una disposición subjetiva de la persona o en una dádiva del poder estatal, sino en la propia naturaleza de ser racional. Este derecho es tan fundamental que puede decirse está a la base de los otros derechos humanos ya que abre a la persona a la trascendencia tanto en el plano horizontal (relación con los demás) como en el vertical (relación con un Absoluto). Este derecho implica el no imponer una religión determinada, superando con ello una visión de cristiandad y legitimando en una sociedad plural la libertad de cultos. Pero también conlleva el no impedir que la persona tenga una opción creyente de su vida y destino, superando con ello un ateísmo o agnosticismo que desde el poder público persigue ideas o compromisos religiosos o reduce la opción de creer al ámbito privado o "de sacristía", eliminando toda manifestación pública de la fe.

\section{Aplicaciones a situaciones concretas y contexto en que se dan}

Desde 1925 Chile vive un régimen de separación entre el Estado y la Iglesia Católica. Con antelación, cuando la religión católica era la oficial del Estado, podía exigir determinados privilegios. Para ser equilibrados, justo es reconocer que ambas partes podían reclamar algunos beneficios. Así, para poner sólo un ejemplo, los párrocos recibían sueldo del Estado y éste proponía a la Santa Sede los nombres de los candidatos al Episcopado. Hoy la situación es diferente y ha permitido una serie de cambios ulteriores: libertad de cultos, otorgamiento de personalidad jurídica a confesiones religiosas que cumplan ciertos requisitos comunes a todas, justificación de la enseñanza religiosa plural en escuelas y liceos municipales, asistencia religiosa plural en centros públicos como cárceles, feriado legal para celebrar el Día Nacional de las Iglesias Evangélicas y Protestantes, etc. Es claro, sin embargo, que nuestro Estado chileno secular no ha podido desconocer una realidad sociológica que evidencian las encuestas y ello es legítimo: casi un $90 \%$ de la población chilena adhiere a una religión, lo que puede implicar la aceptación de Dios o de un Ser Absoluto $^{15}$. Igualmente, si se suma la opción religiosa católica y protestante, según datos del último Censo, poco más del $80 \%$ de la población cree en Jesucristo como Hijo de Dios ${ }^{16}$. No es de extrañar, entonces, que si un Presidente se considera creyente, jure cumplir con fidelidad los deberes de su cargo. Ese juramento testimonia, de modo público, su adhesión de fe en Dios y nadie debiera sentirse "agredido" por esa profesión confesional. Lo mismo puede plantearse cuando una autoridad creyente agradece el auxilio divino después de un episodio conflictivo. En la lógica del pluralismo, otro tanto podría decirse de un Presidente agnóstico o ateo que no jura sino promete cumplir con fidelidad los deberes de su cargo o no agradece la intervención

13 Los destacados pertenecen al autor del artículo.

14 CONCILIO VATICANO II, Declaración sobre libertad religiosa, 2.

15 Según el documento "Chile en Cifras" publicado por el Gobierno de Chile en el 2004, a partir de los datos del Censo de 2002 que maneja el INE la suma de personas que adhieren a una religión dan un porcentaje de 89,62\%. En ese mismo documento se señala que un $8,3 \%$ afirma no tener religión o ser ateo.

16 Cfr. Documento "Chile en Cifras" donde se señala que un 69,96\% de las personas censadas mayores de 15 años se declara católico y un 15,14\% se declara evangélico. Es posible que estos datos hayan variado algo con una cierta disminución de la población católica y un incremento de la población evangélica, precisión que se sabrá en el próximo censo que se está preparando. 
divina en la resolución de un conflicto ${ }^{17}$. Por otra parte, los sucesivos gobiernos han procurado ser muy equilibrados en su participación en actos públicos de contenido religioso. Es el caso de la asistencia de autoridades políticas tanto al Tedeum ecuménico católico como a la misma ceremonia del mundo protestante.

En una sociedad secular muy contraria a manifestaciones religiosas públicas, la lógica es no aceptar la erección de símbolos, imágenes o representaciones de contenido religioso, para cautelar la secularidad del espacio público. Ésta no ha sido la situación que se ha dado en Chile, lo que revela una adecuada aceptación o, al menos, una tolerancia a este tipo de manifestaciones. Es el caso de la imagen de la Virgen del cerro San Cristóbal, las innumerables cruces que están en espacios públicos, la conmemoración (en imágenes y símbolos) de la presencia de Juan Pablo II en nuestra patria, etc. No obstante, algunas sutiles señales dan cuenta de que esta acogida o tolerancia ante la instalación de una imagen religiosa en un lugar público, a pesar de la innegable tradición creyente del país, ya no es tan clara. Ejemplo de esta situación fue el cuestionamiento al proyecto que buscaba erigir una estatua de Juan Pablo II en la plaza pública ubicada frente a la Escuela de Derecho de la Universidad de Chile $^{18}$.

Las manifestaciones públicas de fe de las diversas confesiones religiosas: procesiones, peregrinaciones, predicaciones y celebraciones en espacios públicos, etc., constituyen ya una práctica "pacíficamente adquirida" en Chile. Sólo habría que cautelar, por parte del Estado, una efectiva libertad de culto para todas las confesiones religiosas legalmente constituidas en el país, sin privilegiar una sobre otra. Esta tradición testimonia la adhesión del Estado chileno a una legítima libertad religiosa -coherente con lo expresado en $\mathrm{DH}, 2$ - en cuanto no impide a las personas testimoniar públicamente sus convicciones de fe.

Llegamos a un último aspecto de estas aplicaciones concretas y probablemente de las más controvertidas: las discusiones valóricas en el marco de Estados seculares. Precisando más, la necesidad de plantear -entre nosotros- el papel de la Iglesia Católica en las discusiones valóricas. Como es claro, la reflexión tiene que considerar algunas realidades objetivas y consideraciones, en parte ya mencionadas: el Estado chileno -como la mayoría de los países occidentales ${ }^{19}$ - no es confesional; en nuestra Patria el "peso sociológico" de la Iglesia Católica es innegable, por sobre otras instancias religiosas o filosóficas; hay una renovación de la teología católica que toma cada vez más en serio una legítima autonomía de las realidades temporales; se percibe una curiosa actitud "moderna" de declararse agnóstico aunque no se sea; existe una peculiar tolerancia frente a "agresiones" al sentimiento religioso católico, especialmente en medios de comunicación social, cosa que sería impensable, por ejemplo, en el mundo islámico, etc.

17 Sin entrar en este trabajo en lo que significa teológicamente apelar a "la intervención divina".

18 Las razones para objetar esta erección fueron muy diversas. Entre otras, que la estatua rompía, por sus dimensiones, la armonía del entorno o que el proyecto no contaba -al parecer- con la autorización del Consejo de Monumentos. Podría pensarse, también, en una razón no explicitada y que de hecho no se esgrimió: la erección de la estatua resultaba molesta para personas de otra o de ninguna confesión religiosa. Se sabe que, en definitiva, su instalación se hará en un recinto abierto de la Iglesia Católica.

19 La mantención de países con decisiva injerencia religiosa en la política se da, principalmente, en muchos países del oriente islámico, algunos de los cuales son verdaderas teocracias, bajo apariencia de regímenes democráticos seculares. El caso más extremo fue el régimen talibán en Afganistán. Sin embargo, se mantiene latente, en esos países, una radicalización del enfoque teocrático musulmán por medio de partidos políticos que lo postulan. Pareciera favorecerse esta radicalización en una concepción extrema del Islam que va ganando terreno, una de cuyas manifestaciones es la teología de la "guerra santa" contra Occidente. Es necesario reconocer que el mundo occidental ha avanzado considerablemente en la secularización de la política, salvo minorías, producto de la renovación de la teología en las opciones religiosas occidentales y en la sociología política de esta parte del mundo, cosa que no ha ocurrido en otros países con diversa tradición de influjo religioso o, incluso, de ideologías políticas donde, por esta vía, se introduce una proscripción de una auténtica libertad religiosa. 
Hemos expresado que la Iglesia Católica tiene el derecho a ser un actor más en el debate de las ideas en torno a los valores éticos. No puede pretender ser la única y la más importante voz, pero tampoco debe ser descalificada so pretexto de que está ejerciendo indebidamente su peso sociológico. No es fácil, sin embargo, el discernimiento en este punto, frente a sutiles influencias. Sin embargo, mucho de ese peso sociológico se desplaza a peso moral y ello es reconocido por el mismo Estado chileno: es lo que justifica la invitación de gobiernos de distinto signo político a personeros de la Iglesia Católica a participar en Comisiones en busca de la verdad y la reconciliación, en torno al diálogo cívico-militar, a ejercer su presencia mediadora ante conflictos étnicos, laborales e incluso ante situaciones de mediación internacional. También la Iglesia pide libertad para decir su palabra utilizando "todos y sólo los medios conformes con el Evangelio". Según ello debe emplear la persuasión, el diálogo, la coherencia entre su enseñanza y su actuar concreto, la argumentación desde la razón humana. En este punto conviene decir que el recurso a una "ley natural" no puede apelar -exclusivamente- a su vinculación con la ley divina (que introduciría en el debate el factor religioso, rechazado por parte de algunos dialogantes). Debe apelar a la "recta ratio" humana -que para una persona creyente siempre estará vinculada con Dios. En esta argumentación racional no eliminará su aporte de visión "de integralidad" (apertura a la Trascendencia) -según se vio anteriormente- ofrecido como un elemento del diálogo pero no impuesto.

La pregunta para la misma Iglesia en un debate al interior de una sociedad plural será ¿qué comportamiento es el que humaniza o qué conducta es la que despersonaliza? No será: qué es lo que, como Iglesia, se debe plantear a los católicos ${ }^{20}$, en cuanto creyentes, o qué es necesario que se aplique a la vida pública. La argumentación desde la humanización no aparta a la Iglesia del Evangelio, de lo contrario lo auténticamente humano nunca sería plenamente cristiano, y permite tender puentes de diálogo con las opciones no creyentes. Para hacer concreta esta línea, se pueden proponer algunos ejemplos que tocan temas valóricos: (a) en el debate sobre una educación sexual integral, afirmar que la conducta sexual del educando se vincule con la expresión del amor, no puede ser vista como una proposición católica sino como un elemento que humaniza ese comportamiento. ¡Ya sería valioso que los planes estatales de educación sexual tuvieran en cuenta la relación con el amor cuando los educandos ejercieren su sexualidad! La situarían en una realidad plenamente humana, superando un exclusivo comportamiento genital. (b) en el debate respecto del aborto, la argumentación debiera plantearse en términos de novedad de pertenencia a la especie racional de ese nuevo ser que es el cigoto, distinto a los gametos masculino y femenino que le dieron origen. Ya es un alguien que pertenece a la especie humana y no algo que puede ser tratado como un objeto. (c) La normatividad cristiana que tiene su fundamento en la Sagrada Escritura debiera plantearse hoy, en diálogo con el mundo actual, desde la búsqueda del respeto a los derechos humanos. En efecto, los diez mandamientos tienen un estrecha relación con la valoración de aquellos (por ejemplo, el derecho a la vida con el "no matarás"; el derecho a tener una familia con el "respetar padre y madre"; el derecho a la verdad con el "no mentirás", etc.). La predicación del Evangelio pasa hoy, entre otros aspectos, por exigir el respeto a los derechos humanos, que es un signo de los tiempos del mensaje cristiano. Ello no es un oportunismo pastoral sino una manera de integrar a la cultura del presente el Evangelio, como se hizo en los primeros siglos del cristianismo con la filosofía griega o en el Medievo con la filosofía escolástica.

20 Lo expuesto no implica que la Iglesia nada pueda decir a los católicos que participan de la actividad pública, como si sus convicciones religiosas fueran sólo algo intimista que quedan reducidas al ámbito de "la sacristía". Puede apelar a la conciencia moral de ellos para que sean coherentes con sus convicciones de fe, especialmente en materias que la afectan de modo esencial, pero su argumentación no puede moverse en un plano de coactividad moral que impida a estos católicos, inmersos en la vida pública, ejercer su libertad de conciencia. 
Para concluir, es claro que la Iglesia Católica no puede renunciar, en este diálogo con una cultura secular, a proponer su visión del ser humano y de la sociedad. Si lo hiciera estaría ocultando o mimetizando su aporte. Por ello, no afirmará solamente el imperativo categórico kantiano de considerar al ser humano siempre como fin y nunca como medio. Agregará a ese fundamento racional una valoración teológica: respetar al prójimo se basa en considerar al otro un hermano porque todas las personas son hijas de Dios Padre, es decir, forman parte de la familia de Dios. Es la fraternidad que se basa en una paternidad común y que permite fundamentar de mejor forma la libertad y la igualdad de toda persona. 